UDC 341.6

LBC 67.412 .1

\title{
THE CONCEPT OF COMMON HERITAGE OF MANKIND IN TERMS OF INTERNATIONAL TRIBUNAL FOR THE LAW OF THE SEA
}

\author{
S. Mirzaee \\ Peoples' Friendship University of Russia, Moscow, Russian Federation
}

Introduction. The objective is to analyze the provisions of the Advisory Opinion of February 1, 2011 by the International Tribunal for the Sea Law identifying components of the concept of common heritage of mankind. The authors also broadly investigated the concept of common heritage of mankind in the practice of States and international organizations. Methods. The article used scientific methods which make it easier to identify the main aspects and notions of the study. The research used scientific methods of cognition, i.e. analysis, dialectics and synthesis, the generalization and system-structural method and practiced special methods of science such as legal and technical, historical and forecasting methods. The article has investigated the position of common heritage concept in the advisory opinion delivered by the Chamber, the views of State parties as well as the international organizations and United Nations bodies associated with Law of the Sea and assessed the practical aspects of this concept in the approaches of international law actors. Scientific novelty of the proposed approach to the study is that it comprehensively has reviewed the positions of States, international organizations and bodies, as well as provisions of the advisory opinion in connection with the separation of the elements of the common heritage of mankind concept. At the beginning the concept of common heritage of mankind was largely theoretically analyzed, but as used in the framework of this article the enforcement approach allowed us to identify new elements in this concept. Results of the research can be used in the further theoretical developments in the field of international maritime law and the law of international responsibility.

Key words: common heritage of mankind, international sea law, international environmental law, International Tribunal for the Law of the Sea, pledgery.

УДК 341.6

ББК 67.412 .1

\section{ПОНЯТИЕ ОБЩЕГО НАСЛЕДИЯ ЧЕЛОВЕЧЕСТВА В ТРАКТОВКЕ МЕЖДУНАРОДНОГО ТРИБУНАЛА ПО МОРСКОМУ ПРАВУ}

\author{
С. Мирзаи \\ Российский университет дружбы народов, г. Москва, Российская Федерация
}

\begin{abstract}
Введение: в статье анализируется проблема реализации на практике концепции «общее наследие человечества», которая рассматривается в ООН с 1970-х гг. ХХ в. преимущественно на теоретическом уровне, что вызывает сложность и неоднозначность его применения и толкования в правоприменительной практике. Раскрытие содержания указанной концепции в отношении глубоководного района морского дна за пределами юрисдикции государств, относящегося к «общему наследию человечества» в соответствии с Конвенцией ООН по морскому праву 1982 г., крайне важно, поскольку разведка глубоководных морских полезных ископаемых (в частности полиметаллических конкреций) уже осуществляется, а правовой режим до сих пор не определен. Методы: использованы общенаучные методы исследования, такие как анализ, синтез, сравнение, а также частнонаучные методы исследования: формально-юридический, технико-юридический. Результа-

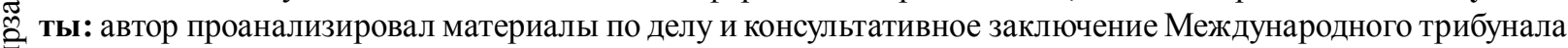
по морскому праву, где была осуществлена трактовка понятия «общее наследие человечества». Выводы: () сформулирован авторский подход к концепции «общее наследие человечества» с целью разъяснения объе-
\end{abstract}


ма ответственности и обязательств государств, поручающихся за частные компании, в рамках их деятельности в отношении глубоководного района морского дна за пределами юрисдикции государств, оценены практические аспекты этого понятия в подходах субъектов международного права.

Ключевые слова: общее наследие человечества, международное морское право, международное экологическое право, Международный трибунал по морскому праву, поручительство.

\section{Введение}

Общее наследие человечества - одно из самых удивительных достижений человеческого разума в области международного права и одно из главных юридических понятий за последние десятилетия. С 1960 г. международное сообщество осознало важность огромного потенциала морских и космических ресурсов и пришло к выводу, что коренное различие между промышленно развитыми и развивающимися государствами способно усилить расхождения между ними. Соответственно одним из важных событий стало объявление части дна морей и океанов, а также их ресурсов вне национальной юрисдикции государств и присвоение им статуса общего наследия человечества [2]. Поскольку только у нескольких государств была возможность с точки зрения технологий использовать богатые ресурсы в этой области, появилась необходимость в механизме, согласно которому все государства на каждом уровне развития были бы способны извлекать выгоду из ресурсов в этих областях. В этой связи Генеральная Ассамблея ООН 17 декабря 1970 г. одобрила резолюцию 2749, озаглавленную «Принципы, регулирующие режим дна морей и океанов и его недр за пределами действия национальной юрисдикции». Согласно ст. 136 Конвенции ООН по морскому праву 1982 г. (далее - Конвенция 1982 г.) дно морей и океанов, а также их недра и ресурсы были выведены за пределы национальной юрисдикции и объявлены общим наследием человечества.

После создания нового правового режима в глубинах морей и океанов возникла проблема использования ресурсов этих областей. Согласно ст. 139 Конвенции 1982 г. все частные компании, стремящиеся расширить деятельность в Районе по глубоководной разработке полезных ископаемых, должны иметь поручителя в лице государства - участника Конвенции.
Согласно п. 4 ст. 4 Приложения III Конвенции государство-поручитель несет ответственность за обеспечение в рамках его правовой системы того, чтобы юридическое лицо, в отношении которого дано такое поручительство, осуществляло свою деятельность в Районе в соответствии с условиями его контракта и обязательствами по Конвенции. Однако в случае, если государство-поручитель приняло законы, правила и административные меры, которые в рамках его правовой системы являются в разумной степени приемлемыми, то оно не несет ответственности за ущерб, вызванный небрежностью юридического лица, в отношении которого данное государство дало поручительство.

В 2010 г. государство Науру запросило Совет Международного органа по морскому дну вынести консультативное заключение у Камеры по спорам, касающимся морского дна, Международного трибунала по морскому праву о смысле главы одиннадцатой Конвенции 1982 года. Суть вопроса Науру состояла в необходимости разъяснить «объем и обязательства, включая проправительственные частные компании, которые осуществляют свою деятельность в Районе» [9].

\section{Концепция}

\section{«общее наследие человечества»}

В конце XX столетия ввиду обнаружения полиметаллических конкреций в глубоководных районах морского дна количество этих ресурсов, а также научно-технический прогресс привели к появлению правового режима «общего наследия человечества», который состоит из пяти основных компонентов: неприсвоение, использование в мирных целях, глобальный учет общих интересов, разделение выгоды от использования и международное управление распределением ресурсов. 1 ноября 1967 г. это понятие было предложено Арвидом Пардо на заседании Генеральной 


\section{МЕЖДУНАРОДНОЕ ПРАВО И СРАВНИТЕЛЬНОЕ ПРАВОВЕДЕНИЕ}

Ассамблеи ООН. Он предложил, чтобы дно морей и океанов и их недра за пределами национальной юрисдикции были объявлены частью общего наследия человечества [1]. Его предложение стало отправной точкой для серии переговоров относительно Конвенции ООН по морскому праву. В 1979 г. Соглашением о деятельности государств на Луне и других небесных телах луна и ее природные ресурсы были признаны частью общего наследия человечества.

\section{Консультативное заключение} Международного трибунала по морскому праву от 1 февраля 2011 г.

1 марта 2010 г. постоянное представительство Республики Науру при ООН представило Генеральному секретарю Международного органа по морскому дну («Органа») предложение с просьбой к Камере дать консультативное заключение по вопросам, касающимся ответственности государствпоручителей.

В данном заявлении было указано следующее: «В 2008 г. Республика Науру одобрила план коммерческой компании Nauru Ocean Resources Inc. об исследовательских работах полиметаллических конкреций в Районе, выступив ее поручителем. Науру, как и большинство других развивающихся государств, еще не обладает технической и финансовой возможностью для добычи полезных ископаемых на морском дне в международных водах.

Для принятия фактического участия в деятельности в Районе государствам приходится привлекать юридических лиц со стороны (аналогично тому, как развивающиеся государства привлекают иностранные прямые капиталовложения). Развивающиеся государства испытывают не только нехватку финансовых средств для добычи полезных ископаемых на морском дне в международных водах, многие из них не в состоянии даже предвидеть потенциальные юридические риски, связанные с таким проектом. Признавая это, поручительство за Nauru Ocean Resources Inc. изначально основывалось на том, что Науру сможет разделить потенциальную ответственность или возместить затраты, возникшие в результате деятельности Nauru Ocean
Resources Inc. Важно предвидеть, насколько при определенных обстоятельствах эта ответственность могла бы превышать финансовые возможности Науру (также как и многих других развивающихся государств). Республика сделала важное концептуальное замечание: в отличие от добычи полезных ископаемых на суше, где государство рискует потерять только то, чем уже обладает (например, при нанесении ущерба окружающей среде на своей территории), при деятельности в Районе государства могут потенциально столкнуться с убытками, превышающими те, на которые они изначально рассчитывали» [9]. Далее Науру указало в своем заявлении, что «...если государство-поручитель несет ответственность за деятельность в Районе, то Науру, как и другие развивающиеся государства, может столкнуться с препятствиями для деятельности в Районе, что приведет к нарушению одной из целей ч. ХІ Конвенции (в том числе ст. 148, 150 (с) и 152 (2)), заключающейся в поощрении эффективного участия развивающихся государств в деятельности в Районе». На основании указанного Науру посчитало крайне важным получить официальное толкование соответствующих разделов ч. ХІ Конвенции 1982 г. по поводу ответственности и обязательств, для того чтобы развивающиеся государства могли оценить, способны ли они эффективно снизить подобные риски, и в свою очередь вынести обоснованное решение, принимать ли участие в деятельности по исследованию Района или нет [9].

Науру направило запрос в Совет с просьбой к Камере дать толкование относительно ряда конкретных вопросов.

6 мая 2010 г. Совет Международного органа по морскому дну принял решение в соответствии со ст. 191 Конвенции 1982 г. отправить запрос в Камеру по спорам, касающимся морского дна, и в Международный трибунал по морскому праву (далее - «Трибунал»), чтобы тот вынес консультативное заключение относительно определенных юридических вопросов, возникающих в процессе деятельности.

В этом решении были сформулированы следующие вопросы: 1) в чем заключаются ответственность и обязательства государств участников Конвенции в отношении поручи- 
тельства за деятельность в Районе в соответствии с Конвенцией, в особенности с ч. XI и Соглашением 1994 г. об осуществлении ч. ХІ Конвенции? 2) в каких пределах возникает ответственность государства-участника в случае невыполнения положений Конвенции, в особенности ч. XI и Соглашения от 1994 г., юридическим лицом, за которое государство поручилось в соответствии со ст. 153 (пар. 2(b)) Конвенции? 3) какие необходимые и надлежащие меры должно предпринимать государство-поручитель для выполнения своих обязанностей по Конвенции, в особенности ст. 139 и Приложения III, и по Соглашению 1994 года?

Государства - участники Конвенции, Орган и межправительственные организации были приглашены к участию в Ассамблее Органа в качестве наблюдателей, чтобы представить свои письменные заявления по вопросам, адресованным Камере.

\section{Понятие}

\section{общего наследия человечества в соответствии с консультативным заключением}

Камера обратила особое внимание на понятие общего наследия человечества при ответе на вопросы, поднятые Советом. При ответе на первый вопрос она рассмотрела случай поручительства, указав, что роль государства-поручителя, как изложено в Конвенции, способствует реализации общих интересов всех государств в вопросе надлежащего применения принципа общего наследия человечества, который требует добросовестного выполнения обязательств, изложенных в ч. XI. Роль общих интересов государства-поручителя подтверждается его обязательством, изложенным в п. 4 ст. 153 Конвенции, для «оказания содействия» Органу, который в соответствии с п. 2 ст. 137 Конвенции действует от имени человечества [5, пар. 76].

Также в части «оценки воздействия на окружающую среду» Камера ссылается на дело «о целлюлозных заводах на реке Уругвай» [4, с. 124-130; 8], касающееся «совместно используемых ресурсов», чтобы дать разъяснения относительно деятельности в Районе, выходя за рамки Правил. Доводы
C. Мирзаи. Понятие общего наследия человечества

Суда о трансграничном характере в вышеупомянутом деле также могут быть отнесены к деятельности, сопряженной с воздействием на окружающую среду, на территории вне пределов национальной юрисдикции. А доводы Суда относительно «совместно используемых ресурсов» также могут быть отнесены к ресурсам, которые являются общим наследием человечества. Таким образом, в свете норм обычного права, упомянутых Судом, можно считать, что оценка воздействия на окружающую среду должна быть включена в систему консультаций и предварительных уведомлений, изложенных в ст. 142 Конвенции, в отношении «месторождений ресурсов в Районе, которые находятся в пределах национальной юрисдикции» [5, пар. 148].

В части «интересов и потребностей развивающихся государств» Камера ссылается на ст. 148 Конвенции, которая учитывает особые интересы и потребности развивающихся государств, как прибрежных, так и не имеющих выхода к морю. Подход Конвенции к этому вопросу особенно очевиден в положениях, допускающих преференциальный режим для развивающихся государств, которые изъявляют желание участвовать в добыче полезных ископаемых в глубоководных районах морского дна, которые зарезервированы для Органа; он очевиден в обязательстве государств способствовать международному сотрудничеству в морских научных исследованиях в Районе, чтобы гарантировать, что программы разработаны «на благо развивающихся государств»; и в обязательстве Органа и государств-участников способствовать передаче технологий развивающимся государствам и подготовке кадров и персонала из развивающихся государств; очевиден в полномочиях, данных Органу в осуществлении его функций, уделять особое внимание развивающимся государствам, несмотря на принцип недискриминации; и в обязательстве Совета принять «во внимание интересы и потребности развивающихся государств», рекомендуя и одобряя нормы, правила и процедуры по совместному использованию финансовых и других выгод, полученных в ходе деятельности в Районе. Однако относительно обязанностей (или ответственности) государства-поручителя в Конвенции нет ни одного положения, «спе- 


\section{МЕЖДУНАРОДНОЕ ПРАВО И СРАВНИТЕЛЬНОЕ ПРАВОВЕДЕНИЕ}

циально предусматривающего» преференциальный режим по отношению к государствупоручителю, являющемуся развивающимся государством. Одинаковое отношение к развивающимся и развитым государствам-поручителям соотносится с необходимостью не допустить недобросовестных действий со стороны коммерческих предприятий, зарегистрированных в развитых государствах и создающих компании в развивающихся государствах, а также физических лиц, получающих гражданство и поручительство в развивающихся государствах в надежде на менее обременительные правила регламентации и контроля. Распространение таких государств-поручителей подвергло бы опасности единообразное применение высоких стандартов защиты морской среды, безопасную деятельность в Районе и защиту общего наследия человечества [5, пар. 156-159].

В ответ на второй вопрос Камера указывает на понятие общего наследия человечества в контексте нанесения ущерба Району. Ни Конвенция, ни соответствующие Правила не дают определения ущербу, подлежащему возмещению, а также не разъясняют, какие субъекты могут требовать компенсации. Рассматриваемый ущерб может включать ущерб Району и его ресурсам, составляющим общее наследие человечества, и ущерб морской среде. Субъектами, наделенными правом требовать компенсации, могут быть Орган, предприятия, занимающиеся разработкой глубоководных районов морского дна, другие субъекты, осуществляющие деятельность в море, а также прибрежные государства. Однако ни одно положение Конвенции непосредственно не предоставляет право Органу предъявить такую претензию. Можно утверждать, что такое право неявно предоставляется в п. 2 ст. 137 Конвенции, где говорится, что Орган действует «от имени» человечества. Каждое государство-участник может быть также наделено правом требовать компенсацию в силу обязательств erga omnes [3], касающихся сохранения окружающей среды открытого моря и Района.

В своих комментариях относительно третьего вопроса Камера заявила, что меры, которые будут предприняты государством-поручителем, должны быть представлены в форме законов, правил и административных методов. Это означает, что государство-поручитель не будет считаться исполнившим свои обязательства только при наличии факта вступления в договорные отношения с юридическим лицом, например, на основе соглашения о поручительстве, поскольку роль государства-поручителя состоит в том, чтобы способствовать общим интересам всех государств в реализации принципа общего наследия человечества, оказывая поддержку Органу и действуя самостоятельно в целях обеспечения надлежащего следования правилам разработки глубоководных районов морского дна со стороны предприятий, находящихся под его юрисдикцией [5, p. 223-226].

\section{Выводы}

До того как Камера по спорам, касающимся морского дна, в Международном трибунале по морскому праву официально вынесла свое консультативное заключение, Часть XI и Приложение III Конвенции ООН по морскому праву 1982 г., а также Соглашение 1994 г. об осуществлении Части ХI Конвенции 1982 г. не были достаточно понятны для государств, стремящихся поддерживать деятельность предприятий в Районе. Учитывая мнение государств-участников и международных организаций, Камере удалось принять во внимание все аспекты и подходы в консультативном заключении, исключив двусмысленные положения из своих предыдущих правил. Роль консультативного заключения значительна, поскольку оно обеспечивает полезное руководство по деятельности в Районе. В частности, консультативное заключение наложило высокие стандарты требований на государства-поручители для выполнения обязательств должной осмотрительности и реализации подхода, основанного на принципе предосторожности. Кроме того, предприятия-подрядчики должны быть готовы проводить оценку воздействия на окружающую среду и реализовать наиболее эффективные методы охраны окружающей среды [6; 7, p. 232]. Темп разработки в Районе существенно увеличился, и, учитывая данное консультативное заключение, государства определили действия, которые исключают их международную ответственность. 
Данное консультативное заключение одно из удачных событий международного права в вопросе применения понятия общего наследия человечества, которое проложит путь для дальнейшего привлечения развивающихся государств к деятельности по разведке и разработке ресурсов в Районе, рассматриваемых как общее наследие человечества. Кроме того, данное консультативное заключение предоставит государственным деятелям мира ясное видение того, что еще множество объектов могут быть причислены к общему наследию человечества и что путь для разработки ресурсов, доступных человечеству, может быть проложен для всех государств, независимо от их географического положения и экономического статуса.

\section{СПИСОК ЛИТЕРАТУРЫ}

1. Абашидзе, А. Х. Консультативное заключение Международного трибунала по морскому праву об ответственности государств за деятельность на морском дне за пределами национальной юрисдикции / А. Х. Абашидзе, А. М. Солнцев, М. Д. Сюняева // Государство и право. - 2012. - № 7. - С. 72-82.

2. Даниленко, Г. М. Концепция общего наследия человечества в международном праве / Г. М. Даниленко, В. М. Постышев // Советское государство и право. - 1988. - № 6. - С. 89-106.

3. Солнцев, А. М. Обязательство erga omnes в международном экологическом праве / А. М. Солнцев // Вопросы права и экономики. - 2015. - № 5 (83). - C. 39-43.

4. Солнцев, А. М. Практикум по международному экологическому праву / А. М. Солнцев. - М. : РУДН, 2011.-159 c.

5. Advisory opinion «Responsibilities and obligations of States sponsoring persons and entities with respect to activities in the Area», 2011. - Electronic text data. - Mode of access: https://www.itlos.org/ fileadmin/itlos/documents/cases/case no 17/17 adv_op_010211_en.pdf(date of access: 11.09 .2016$).-$ Title from screen.

6. Gao, J. The responsibilities and obligations of the sponsoring States advisory opinion / J. Gao // Chinese Journal of International Law. - 2013. - № 12 (4). - P. 771-786.

7. Jamali, H. R. Common heritage of mankind: the concept and application in international law / H. R. Jamali. - Tehran : Farhang-Shenasi Press, 2011.
8. Pulp mills on the River Uruguay (Argentina v. Uruguay), 2006 I.C.J. Rep. 156; 2007. - Electronic text data. - Mode of access: http://archivo.presidencia. gub.uy/sci/noticias/2010/04/fallo_haya.pdf. - Title from screen.

9. Request for advisory opinion, 2010. Electronic text data. - Mode of access: https:// www.itlos.org/fileadmin/itlos/documents/cases/ case_no_17 Letter_from_ISBA_14_10_2010_E.doc.pdf (date of access: 11.09.2016). - Title from screen.

\section{REFERENCES}

1. Abashidze A.Kh., Solntsev A.M., Syunyaeva M.D. Konsultativnoe zaklyuchenie Mezhdunarodnogo tribunala po morskomu pravu ob otvetstvennosti gosudarstv za deyatelnost na morskom dne za predelami natsionalnoy yurisdiktsii [The advisory opinion of the International Tribunal for the Law of the Sea on the responsibility of States for activities in the sea beyond national jurisdiction]. Gosudarstvo i pravo, 2012, no. 7, pp. 72-82.

2. Danilenko G.M., Postyshev V.M. Kontseptsiya obshchego naslediya chelovechestva $v$ mezhdunarodnom prave [Conception of common heritage of mankind in international law]. Sovetskoe gosudarstvo i pravo, 1988, no. 6, pp. 89-106.

3. Solntsev A.M. Obyazatelstvo erga omnes v mezhdunarodnom ekologicheskom prave [Erga omnes obligations in international environmental law]. Voprosy prava i ekonomiki, 2015, no. 5 (83), pp. 39-43.

4. Solntsev A.M. Praktikum po mezhdunarodnomu ekologicheskomu pravu [Workshop on International Environmental Law]. Moscow, RUDN Publ., 2011.159p.

5. Advisory Opinion "Responsibilities and obligations of States sponsoring persons and entities with respect to activities in the Area", 2011. Available at: https://www.itlos.org/fileadmin/itlos/documents/ cases/case_no_17/17_adv_op_010211_en.pdf. (accessed September 11, 2016).

6. Gao J. The Responsibilities and Obligations of the Sponsoring States Advisory Opinion. Chinese Journal of International Law, 2013, no. 12 (4), pp. 771-786.

7. Jamali H.R. Common Heritage of Mankind: The Concept and Application in International Law. Tehran, Farhang-Shenasi Press, 2011.

8. Pulp Mills on the River Uruguay (Argentina v. Uruguay), 2006 I.C.J. Rep. 156; 2007.

9. Request for Advisory Opinion, 2010. Available at: https://www.itlos.org/fileadmin/itlos/documents/ cases/case_no_17/Letter_from_ISBA_14_10_ 2010_E.doc.pdf. (accessed September 11, 2016). 


\section{Information About the Author}

Siavash Mirzaee, Postgraduate Student, Department of International Law, Peoples' Friendship University of Russia, Miklukho-Maklaya St., 6, 117198 Moscow, Russian Federation, Siavash.mirzaei1988@gmail.com.

\section{Информация об авторе}

Сиаваш Мирзаи, аспирант кафедры международного права, Российский университет дружбы народов, ул. Миклухо-Маклая, 6, 117198 г. Москва, Российская Федерация, Siavash.mirzaei1988@gmail.com. 